\title{
Topical lodine-Induced Thyrotoxicosis in a Newborn with a Giant Omphalocele
}

\author{
Sonali Malhotra, MD ${ }^{1}$ Shilpa Kumta, MD ${ }^{1} \quad$ Alok Bhutada, MD ${ }^{2} \quad$ Elka Jacobson-Dickman, MD ${ }^{1}$ \\ Roja Motaghedi, MD ${ }^{1}$
}

${ }^{1}$ Department of Pediatric Endocrinology, Infant and Children's Hospital of Brooklyn, Maimonides Medical Center, Brooklyn, New York

2 Department of Neonatology, Infant and Children's Hospital of Brooklyn, Maimonides Medical Center, Brooklyn, New York

\begin{abstract}
Address for correspondence Roja Motaghedi, MD, Department of Pediatric Endocrinology, Infant and Children's Hospital of Brooklyn, Maimonides Medical Center, 977 48th street, Brooklyn, NY 11219 (e-mail: rojamotaghedi@gmail.com; rmotaghedi@maimonidesmed.org).
\end{abstract}

Am J Perinatol Rep 2016;6:e243-e245.

\begin{abstract}
Keywords

- neonate

- thyrotoxicosis

- topical povidoneiodine

- giant omphalocele

Introduction Neonatal thyrotoxicosis is a life-threatening condition with potentially irreversible neurologic sequelae. Most cases are seen in neonates born to mothers with Graves' disease. Topical iodine-induced hypothyroidism has been reported in neonates, but iodine-induced neonatal hyperthyroidism has not been described; albeit a familiar entity in adults.

Case Description Herein we present a unique case of a neonate, born with a giant omphalocele, who was treated with topical povidone-iodine dressings to promote escharification, in preparation for delayed surgical closure. By third day of life (DOL), the baby presented with a suppressed thyroid stimulating hormone of $0.59 \mu \mathrm{lU} / \mathrm{mL}$, elevated free thyroxine of $5.63 \mathrm{ng} / \mathrm{dL}$, and frank cardiovascular manifestations of thyrotoxicosis. After replacement of the topical iodine dressings with iodine-free silver sulfadiazine, the thyroid status gradually improved with complete resolution of hyperthyroidism by 17 th DOL.

Conclusion This case emphasizes that significant topical iodine exposure can result in both hypothyroidism and hyperthyroidism, and therefore, vigilance in monitoring thyroid function is imperative.
\end{abstract}

Neonatal thyrotoxicosis is an uncommon but portentous condition, characterized by elevation of the active thyroid hormones in the circulation and clinical manifestation of hyperthyroidism.

If left untreated, it can lead to irreversible neurologic sequelae. ${ }^{1,2}$ The most common etiology is maternal Graves' disease, occurring as a result of transplacental transfer of the thyroid stimulating immunoglobulins (TSI) from mother to the fetus. Subsequently, TSI stimulates the thyroid stimulating hormone (TSH) receptor on fetal thyroid gland to produce excess of free thyroxine (FT4). ${ }^{3}$

Other non-transient neonatal hyperthyroidism can be caused by a dominantly inherited activating mutations in the TSH receptor gene, ${ }^{4}$ in isolation, as well as by an early embryonic postzygotic somatic activating mutation in the adenylate cyclase-stimulating $\mathrm{G} \alpha$ protein gene, ${ }^{5}$ both resulting in constitutionally active stimulatory $\alpha$ subunit of the $G$ protein receptor and involvement of multiple organs. ${ }^{5}$ The presence of activating mutations of the TSH receptor results in permanent thyrotoxicosis. ${ }^{4}$

Iodine excess, whether topical, oral, or intravenous through radiocontrast agents, can lead to thyrotoxicosis as well. This effect is described as the Jod-Basedow phenomenon, which is the consequence of failed thyroid autoregulation during iodine excess, subsequently leading to increased production of thyroid hormones and clinical thyrotoxicosis. To date, multiple cases of thyrotoxicosis are reported in adult received

April 5, 2016

accepted after revision

May 16, 2016
DOI http://dx.doi.org/

10.1055/s-0036-1584879. ISSN 2157-6998.
Copyright $\odot 2016$ by Thieme Medical Publishers, Inc., 333 Seventh Avenue, New York, NY 10001, USA. Tel: +1(212) 584-4662.
License terms

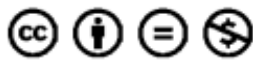


patients exposed to copious topical iodine. On the other hand, in neonates, there are only two reported cases of neonatal hypothyroidism associated with topical iodine treatment, 6,7 while the thyrotoxicosis has never been documented in this age range. Therefore, our case represents the first report of topical iodine-induced neonatal hyperthyroidism.

\section{Case Report}

The patient was a premature female newborn born at 34 weeks of gestation with a giant omphalocele. She presented, at day of life (DOL) 3, with hyperthyroidism while undergoing conservative omphalocele management with daily topical povidone-iodine dressings. Her mother did not have a history of chronic lymphocytic autoimmune thyroiditis or Graves' disease, and has never been on any medications or over-the-counter supplementation.

Prenatal ultrasound at 20 weeks of gestation demonstrated multiple congenital anomalies, including a giant omphalocele. The karyotype was that of a normal 46XX female. Due to premature onset of labor, the baby was delivered at 34 weeks by vaginal delivery. Apgar scores at birth were 5 at 1 minute, 6 at 5 minutes, and 7 at 10 minutes. Due to lack of consistent spontaneous breathing and deep cyanosis with crying, the baby was immediately intubated resulting in improved respiratory status. After birth, baby was confirmed to have thoracolumbar scoliosis and a giant omphalocele with the liver and intestines contained in the intact sac, and a large Wharton's jelly. Considering the size of this lesion, conservative management with daily povidone-iodine dressings was initiated and delayed surgical closure of omphalocele was planned at 1 year of age. Topical povidone-iodine was used at $10 \%$ concentration to promote escharification and epithelialization of the omphalocele sac; 3 to 4 povidone-iodine soaked gauges per day were used to cover the sac starting at birth.

Thyroid function tests were obtained on DOL 3; TSH was suppressed $(0.59 \mu \mathrm{IU} / \mathrm{mL}$; reference range, $0.73-4.60 \mu \mathrm{IU} / \mathrm{mL})$ and FT4 was elevated (5.63 ng/dL; reference range, 0.58-1.64 $\mathrm{ng} / \mathrm{dL}$ ). By DOL 4, the newborn was symptomatic with frank cardiovascular manifestations, including tachycardia (pulse rate, 190-200 bpm) as well as hypertension (blood pressure, 96-105/49-66 mm Hg). On DOL 5, povidone-iodine was stopped completely and replaced with topical silver sulfadiazine. In consideration of the possibility of neonatal Graves' disease (i.e., maternally inherited TSI), TSI level was obtained and was negative (32\%; reference range $<140 \%$ baseline).

The decision was made to monitor the cardiovascular parameters closely along with the thyroid function tests every 24 hours. Considering the negative TSI antibody and with the presumption that this was a transient hyperthyroid state, antithyroid treatment in the form of methimazole was deferred. However, due to sympathetic hyper dynamic state, presenting as tachycardia and hypertension, conferred by the hyperthyroidism, propranolol was initiated in the interim at $0.04 \mathrm{mg} / \mathrm{kg} /$ day.

Within two days of discontinuing the iodine containing dressings, a downward trend of FT4 was noted ( - Fig $\mathbf{1}$ ). Blood pressure and heart rate subsequently normalized, and pro-

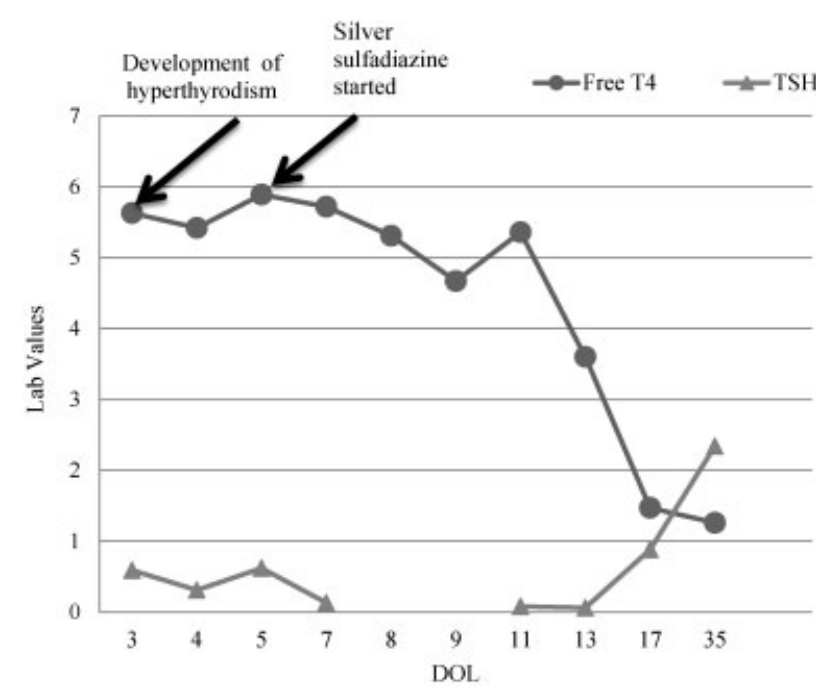

Fig. 1 Transition from hyperthyroid to euthyroid state after stopping povidone iodine dressings. (TSH in $\mu \mathrm{lU} / \mathrm{mL}$ and FreeT4 in $\mathrm{ng} / \mathrm{dL}$ ). TSH, thyroid stimulating hormone.

pranolol was stopped after a total of eight days. By DOL 17, twelve days after ceasing the iodine containing dressing applications, the baby was both clinically and biochemically euthyroid with a FT4 of $1.47 \mathrm{ng} / \mathrm{dL}$ and a TSH of $0.88 \mu \mathrm{IU} / \mathrm{mL}$. (-Table 1). A subsequent follow-up of the thyroid function at DOL 35 revealed continued euthyroid status (FT4, $1.26 \mathrm{ng} / \mathrm{dL}$, FT3, $2.34 \mathrm{pg} / \mathrm{mL}$, and TSH, $2.21 \mathrm{IU} / \mathrm{mL}$ ).

\section{Discussion}

We present a case of iodine-induced neonatal hyperthyroidism with overt clinical manifestations of hyper dynamic cardiovascular state. Clinical and biochemical hyperthyroidism completely resolved twelve days after the discontinuation of iodine-containing dressings, without antithyroid drugs.

Table 1 Changes in the levels of free T4, free T3, and TSH at different days of life

\begin{tabular}{|l|l|l|l|}
\hline DOL & FT4 $(\mathrm{ng} / \mathrm{dL})$ & $\mathrm{FT3}(\mathrm{pg} / \mathrm{mL})$ & $\mathrm{TSH}(\mu \mathrm{lU} / \mathrm{mL})$ \\
\hline 3 & 5.63 & & 0.59 \\
\hline 4 & 5.42 & 2.29 & 0.31 \\
\hline 5 & 5.89 & 2.51 & 0.62 \\
\hline 7 & 5.72 & 2.4 & 0.13 \\
\hline 8 & 5.31 & 2.38 & - \\
\hline 9 & 4.67 & 2.11 & - \\
\hline 11 & 5.36 & - & 0.08 \\
\hline 13 & 3.6 & - & 0.06 \\
\hline 17 & 1.47 & - & 0.88 \\
\hline 35 & 1.26 & 2.21 & 2.34 \\
\hline
\end{tabular}

Abbreviations: DOL, day of life; FT3, free T3; FT4, free T4; TSH, thyroid stimulating hormone. 
Giant omphaloceles, especially when containing liver tissue, as in our patient, remain a therapeutic challenge to pediatric surgeons and neonatologists due to the large area of the defect. Topical iodine is used for desiccation and escharification of the sac; therefore, it is an important conservative measure in the management of large omphaloceles. Whitehouse et al reported six cases of giant omphaloceles treated with povidone-iodine that underwent weekly and then monthly thyroid function monitoring. Out of the six patients, one demonstrated persistent hypothyroidism and subsequently died secondary to cardiac complications. Five patients had no thyroid function perturbation and ultimately achieved fascial closure. ${ }^{6}$ A second report by Cosman et al described a neonate who developed hypothyroidism when a giant omphalocele was conservatively managed by topical iodine. ${ }^{7}$

This previously mentioned phenomenon resulting in hypothyroidism is known as the Wolff-Chaikoff effect, when there is a compensatory down regulation of the sodium-iodide symporter in the thyroid gland in the event of excessive iodide levels, resulting in low levels of circulating thyroid hormones. ${ }^{8}$ In contrast, the Jod-Basedow phenomenon is when iodine overexposure leads to thyrotoxicosis, and is described as an autonomous thyroid state associated with loss of the normal regulatory control of the hypothalamic-pituitary-thyroid axis ${ }^{9}$; the precise mechanism of thyroid hyper function is unclear. The failure of autoregulation of hypothalamic-pituitary-thyroid axis in the event of exposure to high amount of iodine in neonates and children is rare, whereas it has been reported in few adult cases. In these cases, the iodine exposures were typically dietary supplements and iodine-containing medications, including topical iodine antiseptic solutions and intravenous contrast radiographic agents. Additionally in the adult patients, it has been proposed that iodine-induced thyrotoxicosis is more likely associated with underlying multinodular goiters, however, our newborn patient had no identifiable underlying thyroid abnormality. $^{10-12}$

\section{Conclusion}

Our case demonstrates that copious topical iodine exposure can lead to thyrotoxicosis in newborns, even in the absence of an underlying thyroid abnormality. Presumably, this impact might be even more pronounced in newborns considering the larger body surface area to volume ratio, especially if iodine exposure is across denuded skin and/or other mucosal surfaces with high absorptive potential. The knowledge and understanding of the mechanisms involved are critical in optimal management of affected newborns and to prevent fatal outcomes. In the circumstance when such treatments are required, it is imperative for the clinician to monitor thyroid function tests frequently and closely.

\section{References}

1 Zimmerman D. Fetal and neonatal hyperthyroidism. Thyroid 1999;9(7):727-733

2 Aslam M, Inayat M. Fetal and neonatal Graves disease: a case report and review of the literature. South Med J 2008;101(8): 840-841

3 Batra CM. Fetal and neonatal thyrotoxicosis. Indian J Endocrinol Metab 2013;17(1, Suppl 1):S50-S54

4 Thomas JS, Leclere J, Hartemann P, et al. Familial hyperthyroidism without evidence of autoimmunity. Acta Endocrinol (Copenh) 1982;100(4):512-518

5 Ogilvy-Stuart AL. Neonatal thyroid disorders. Arch Dis Child Fetal Neonatal Ed 2002;87(3):F165-F171

6 Whitehouse JS, Gourlay DM, Masonbrink AR, et al. Conservative management of giant omphalocele with topical povidone-iodine and its effect on thyroid function. J Pediatr Surg 2010;45(6): 1192-1197

7 Cosman BC, Schullinger JN, Bell JJ, Regan JA. Hypothyroidism caused by topical povidone-iodine in a newborn with omphalocele. J Pediatr Surg 1988;23(4):356-358

8 Wolff J, Chaikoff IL. Plasma inorganic iodide as a homeostatic regulator of thyroid function. J Biol Chem 1948;174(2): 555-564

9 El-Shirbiny AM, Stavrou SS, Dnistrian A, Sonenberg M, Larson SM, Divgi $C R$. Jod-Basedow syndrome following oral iodine and radioiodinated-antibody administration. J Nucl Med 1997;38(11): 1816-1817

10 Shetty KR, Duthie EH Jr. Thyrotoxicosis induced by topical iodine application. Arch Intern Med 1990;150(11):2400-2401

11 Rajatanavin R, Safran M, Stoller WA, Mordes JP, Braverman LE. Five patients with iodine-induced hyperthyroidism. Am J Med 1984; 77(2):378-384

12 Rath T, Meissl G. Induction of hyperthyroidism in burn patients treated topically with povidone-iodine. Burns 1988;14(4): $320-322$ 